\title{
Experimental study of atmospheric 3D dispersion of a passive tracer in urban environment: comparison with Briggs urban model
}

\author{
M. Francis, D. Maro, O. Connan, D. Hebert, M. Goriaux, \\ B. Letellier \& P. Defenouillere \\ Laboratoire de Radioécologie de Cherbourg-Octeville, \\ Institut de Radioprotection et de Sureté Nucléaire, France
}

\begin{abstract}
FluSAP 2010, a part of a large federative research program Vegdud (2010-2013) funded by the French National Research Agency, is an experimental campaign aiming to improve our knowledge on the dispersion of a plume in heterogeneous urban zones. For this, the French Institute for Radiological Protection and Nuclear Safety (IRSN) conducted an experimental campaign in the city of Nantes (France) to study atmospheric dispersion. A gas tracer $\mathrm{SF}_{6}$ was released in the atmosphere and measured at different altitudes (from 1 to $100 \mathrm{~m}$ ) by using a mast and a small tethered balloon. This allows determining the plume vertical dispersion in an urban area as a function of atmospheric turbulence. A sampling system was also used at ground (1 m height) in order to evaluate the plume horizontal dispersion. All these systems were placed at a distance from the emission point between 20 and $1150 \mathrm{~m}: 30 \mathrm{SF}_{6}$ emissions were performed between May 18 and May 27, 2010.

High compatibility was found between experimental horizontal and vertical widths of the plume and Briggs urban model for the stability class B, C and D according to Pasquill classification. However, this compatibility was only confirmed for small distances from the source (till $370 \mathrm{~m}$ ). For higher distances from the source, it is hard to draw significant conclusions.
\end{abstract}

Keywords: atmospheric dispersion, experimental campaign, urban zone, Briggs urban model. 


\section{Introduction}

Chronic or accidental releases of radioactive contaminants in the environment could be transported to humans by the atmosphere, by fresh water, by marine water and by ground water. In case of accidental release the atmosphere present the faster way for the radionuclide to be transported to human. In fact, the radionuclide velocity in the atmosphere is higher than in other area (Crabol [2]). It is thus important to well understand and to predict the atmospheric dispersion of these contaminants. Several operational models could be recommended such as the models of Doury [3], Pasquill [4], ADMS (CERC [5]) and Briggs [6]. However, it is a difficult challenge to reduce the uncertainty of these models to obtain accurate predictions. Experimental database takes into account many environmental parameters (rural, urban, marine ...) and the micrometeorology is necessary for increasing the model accuracy and for their validation.

In this paper we compare experimental measurements of ATC (Atmospheric Transport Coefficient) and horizontal and vertical standard deviation of a gas tracer $\mathrm{SF}_{6}$ with a Gaussian model: Briggs urban model. The Briggs urban model predicts the ATC and the standard deviation of horizontal and vertical dispersion of a plume, defined from experimental campaigns held in St. Louis in 1962 (McElroy and Pooler [7]).

\section{Experimental campaign}

IRSN performed a number of releases at different distances from the sampling systems. The release location was chosen depending on the wind direction in order to have the sampling horizontal and vertical systems perpendicular to the axe of air direction. Figure 1 shows the studied area in the city of Nantes (west of

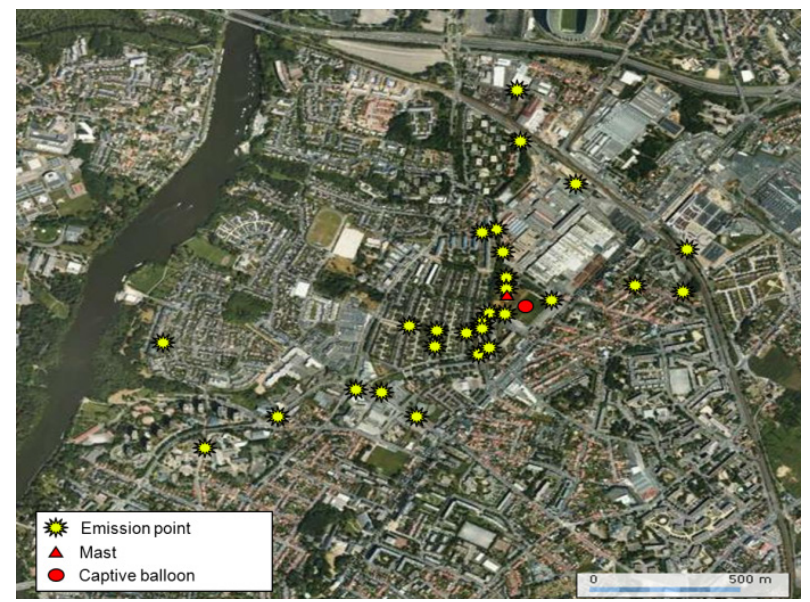

Figure 1: Location of mast/ balloon and releases point. 
France). The distance from the emission point to the sampling system varied between 20 and $1150 \mathrm{~m}$. Total number of emissions was 30 and exploitable ones was 25 (the five non exploitable emissions was due to the change of the wind direction during the measurements).

\subsection{Atmospheric tracer release}

As a gas tracer, the $\mathrm{SF}_{6}$ (sulphur hexafluoride) was chosen because it is a passive and anthropogenic gas. In addition, $\mathrm{SF}_{6}$ could be detected at low concentrations $(50 \mathrm{ppt})$. That is the reason why other authors have also chosen the $\mathrm{SF}_{6}$ as a gas tracer for their experimental campaigns (Connan et al . [8], Finn et al . [9], Hanna and Baja [10], Britter et al. [11]). The release duration was 10 to $20 \mathrm{~min}$ for a flow rate from 0.1 to $5.9 \mathrm{~g} \mathrm{~s}^{-1}$. An $\mathrm{SF}_{6}$ cylinder (Messer SA, France) was used and was connected to a mass flowmeter (Sierra 820) calibrated for $\mathrm{SF}_{6}$ gas. The system was installed into a car and the release was made through a tube fixed at the top of the car $(1.5 \mathrm{~m})$. A fan was placed near the release point to help the dispersion of the gas. In order to have a constant release rate an operator monitored the flow rate during the entire length of each release.

\subsection{Sampling system and meteorological measurements}

To measure the $\mathrm{SF}_{6}$ concentration in the air at different altitude air sampling was performed using automated system composed mainly of a pump and a flow meter (DIAPEG). The samples are made in bags made of Tedlar bag of 11 . The sampling time was 10 to $30 \mathrm{~min}$. The bags were inflated from different altitude by using a mast: 6 sampling levels between 1 and $27 \mathrm{~m}$; or by using a balloon: 6 sampling levels between 1 and 100 meter. The release point was chosen

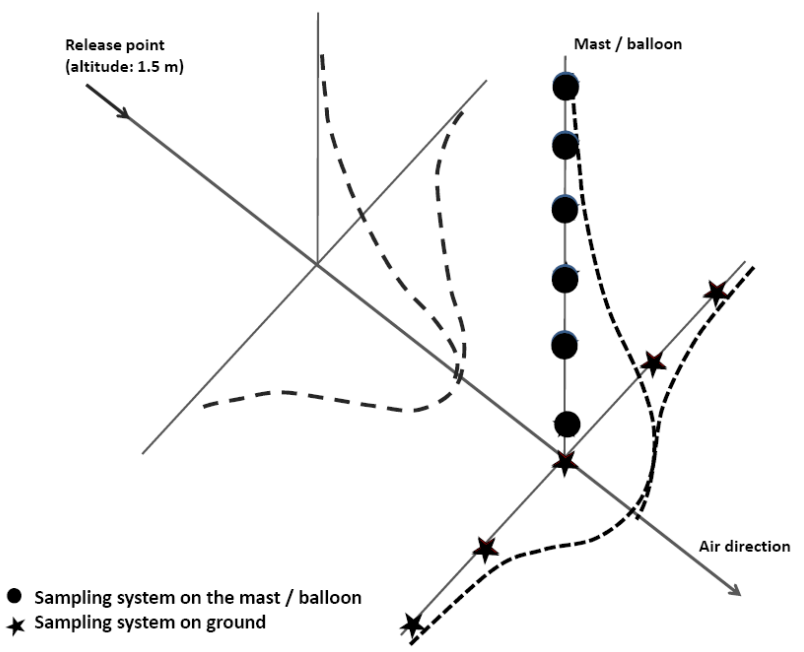

Figure 2: Position of horizontal and vertical sampling systems depending on the wind direction. 
according to the wind direction in order to have the mast/ balloon in the wind axis direction. Other sampling systems were placed horizontally perpendicular to the axe of the wind (Figure 2). The location of each sampling device was determined by using a GPS. To calculate the $\mathrm{SF}_{6}$ concentration, a gas chromatography system was used. For more information on the chromatography system the reader can check (Connan et al. [8]).

At the top of the mast ( $27 \mathrm{~m}$ height) an ultrasonic anemometer (Metek, USA1) was used to give the meteorological information: wind direction and velocity. These data allowed the calculation of turbulence parameters: friction velocity $\mathrm{u} *$, kinematic heat flux H, Monin-Obukhov length LMO. The LMO was used to obtain the stability class according to Pasquill classification.

\section{Briggs urban model}

Briggs urban model is Gaussian plume atmospheric dispersion model and requires a short calculation time Briggs G.A. $[6,12]$. Briggs urban model is used to predict the Atmospheric Transfer Coefficients ATC (see section below) and the vertical and horizontal dispersion of a plume.

Standard deviation calculated with Briggs urban model depends on the distance of measurements and stability conditions.

The equation of the standard deviation considering rural/urban area has been determined from experimental campaigns (equation (1)):

$$
\sigma_{y, z}=a_{y, z} x\left(1+b_{y, z} x\right)^{c_{y, z}}
$$

$y$ and $z$ indicated respectively the horizontal and the vertical standard deviation, $x$ is the distance to the release, $a, b$ and $c$ depend on the stability conditions as given by the Pasquill model and on the area (rural or urban).

\section{Experimental data}

The Atmospheric Transfer Coefficients (ATC) could be calculated by using the measurements of $\mathrm{SF}_{6}$ and is defined by equation (2):

$$
A T C=\frac{\int_{t_{0}}^{t_{1}} X(M, t) \cdot d t}{\int_{t_{0}}^{t_{1}^{\prime}} q(t) \cdot d t}
$$

where $\mathrm{X}(\mathrm{M}, \mathrm{t})$ is the $\mathrm{SF}_{6}$ concentration $(\mathrm{ppb}), \mathrm{q}(\mathrm{t})$ is the $\mathrm{SF}_{6}$ release rate in $\mathrm{m}^{3} \cdot \mathrm{s}^{-1}, \mathrm{t}_{0}$ and $\mathrm{t}_{1}$ are the start and finish times of the measurement and $\mathrm{t}^{\prime}{ }_{0}$ and $\mathrm{t}^{\prime}{ }_{1}$ are the start and finish times of source emission in seconds.

The horizontal and vertical standard deviations of the plume dispersion is obtained by fitting a Gaussian curve respectively to the experimental data of the ATC with respect to the distance perpendicular to the axe of the wind direction 
and by fitting a Gaussian curve to the ATC with respect to the altitude. The horizontal and vertical standard deviations are then deduced from the fitted Gaussian curves Maro et al. [13].

Figure 3 and 4 show an example for the horizontal and vertical profiles of ATC respectively with fitted Gaussian curves.

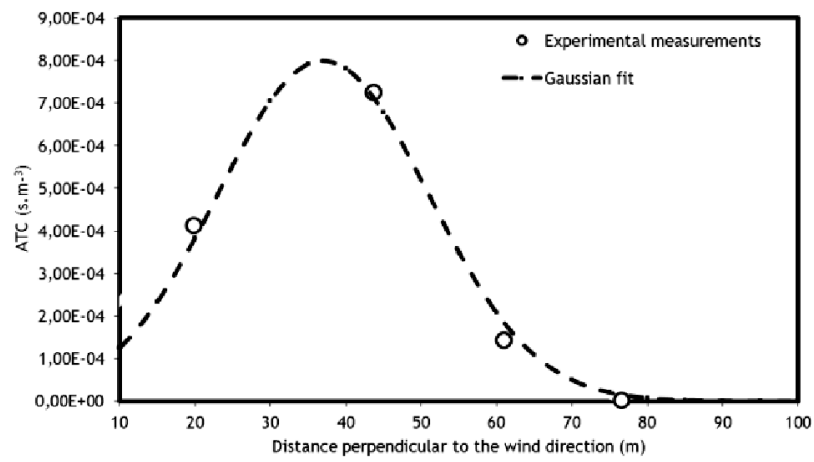

Figure 3: ATC $\left(\mathrm{m}_{\mathrm{s}} \mathrm{s}^{-3}\right)$ with respect to the distance perpendicular to the wind direction experimental measurements and fitted Gaussian curve.

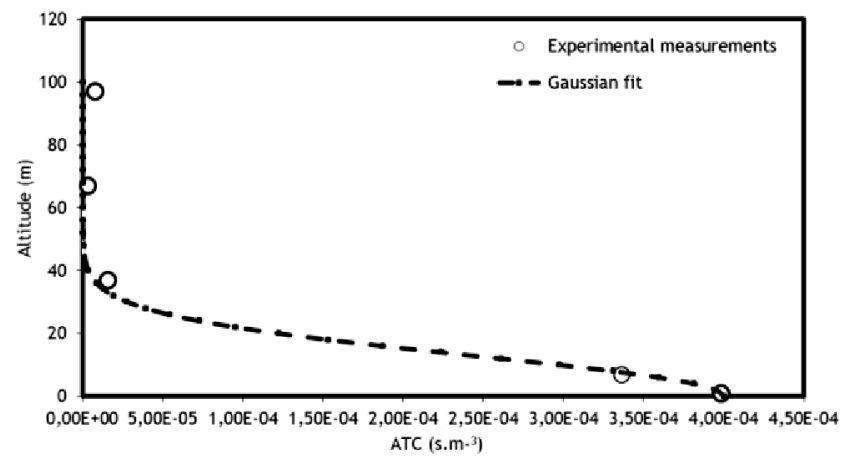

Figure 4: ATC $\left(\mathrm{m}_{\mathrm{s}} \mathrm{s}^{-3}\right)$ with respect to altitude (m): experimental measurements and fitted Gaussian curve.

Table 1 shows the horizontal and vertical standard deviation and the maximal horizontal ATC calculated with equation (2) for each experiment (different distances from release point), for stability class B according to Pasquill classification.

For high distances, fitting a Gaussian curve was not possible so the standard deviation (horizontal/vertical) could not been obtained this will be discussed in the next section. 
Table 1: Experimental ATC $\left(\mathrm{s}^{-\mathrm{m}^{-3}}\right), \sigma_{\mathrm{y}}(\mathrm{m})$ and $\sigma_{\mathrm{z}}(\mathrm{m})$ deduced for each release for a stability class $\mathrm{B}$ according to Pasquill classification.

\begin{tabular}{cccccc}
\hline Date & $\begin{array}{c}\text { Distance from } \\
\text { release }(\mathrm{m})\end{array}$ & $\begin{array}{c}\text { Stabilit } \\
\text { y class }\end{array}$ & $\begin{array}{c}\text { ATC } \\
\left(\mathrm{s} . \mathrm{m}^{-3}\right)\end{array}$ & $\sigma_{\mathrm{y}}(\mathrm{m})$ & $\sigma_{\mathrm{z}}(\mathrm{m})$ \\
\hline $18 / 05 / 11$ & 170 & B & $4.43 \times 10^{-5}$ & 54 & \\
$19 / 05 / 11$ & 20 & B & $8.73 \times 10^{-4}$ & 5 & 5 \\
$19 / 05 / 11$ & 43 & B & $5.50 \times 10^{-4}$ & 18 & 43 \\
$20 / 05 / 11$ & 130 & B & $2.36 \times 10^{-5}$ & 40 & 130 \\
\hline
\end{tabular}

Table 2 shows the horizontal and vertical standard deviation and the maximal horizontal ATC calculated with equation 2 for each experiment (different distances from release point, for stability class $\mathrm{C}$ according to Pasquill classification.

Table 2: $\quad$ Experimental horizontal ATC $\left(\mathrm{s} . \mathrm{m}^{-3}\right), \sigma_{\mathrm{y}}(\mathrm{m})$ and $\sigma_{\mathrm{z}}(\mathrm{m})$ deduced for each release for a stability class $\mathrm{C}$ according to Pasquill classification.

\begin{tabular}{cccccc}
\hline Date & $\begin{array}{c}\text { Distance } \\
\text { from } \\
\text { release }(\mathrm{m})\end{array}$ & $\begin{array}{c}\text { Stability } \\
\text { class }\end{array}$ & $\begin{array}{c}\text { ATC } \\
\left(\mathrm{s} . \mathrm{m}^{-3}\right)\end{array}$ & $\sigma_{\mathrm{y}}(\mathrm{m})$ & $\sigma_{\mathrm{z}}(\mathrm{m})$ \\
\hline $25 / 05 / 11$ & 200 & $\mathrm{C}$ & $7.72 \times 10^{-5}$ & 32 & 35 \\
$25 / 05 / 11$ & 230 & $\mathrm{C}$ & $2.56 \times 10^{-5}$ & 42 & \\
$25 / 05 / 11$ & 120 & $\mathrm{C}$ & $4.25 \times 10^{-4}$ & 28 & 20 \\
$26 / 05 / 11$ & 320 & $\mathrm{C}$ & $1.75 \times 10^{-6}$ & 58 & 50 \\
$26 / 05 / 11$ & 130 & $\mathrm{C}$ & $7.86 \times 10^{-5}$ & 35 & 34 \\
\hline
\end{tabular}

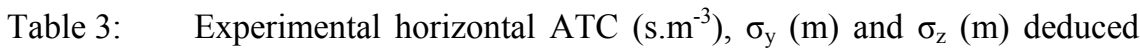
for each release for a stability class $\mathrm{D}$ according to Pasquill classification.

\begin{tabular}{cccccc}
\hline Date & $\begin{array}{c}\text { Distance } \\
\text { from release } \\
(\mathrm{m})\end{array}$ & $\begin{array}{c}\text { Stability } \\
\text { class }\end{array}$ & $\begin{array}{c}\text { ATC } \\
\left(\mathrm{s.m}^{-3}\right)\end{array}$ & $\sigma_{\mathrm{y}}(\mathrm{m})$ & $\begin{array}{c}\sigma_{\mathrm{z}} \\
(\mathrm{m})\end{array}$ \\
\hline $26 / 05 / 11$ & 330 & $\mathrm{D}$ & $4.92 \times 10^{-5}$ & 50 & \\
$26 / 05 / 11$ & 154 & $\mathrm{D}$ & $1.40 \times 10^{-4}$ & 24 & 20 \\
$27 / 05 / 11$ & 40 & $\mathrm{D}$ & $7.25 \times 10^{-4}$ & 12 & 10 \\
$27 / 05 / 11$ & 124 & $\mathrm{D}$ & $0.90 \times 10^{-4}$ & 18 & \\
$27 / 05 / 11$ & 367 & $\mathrm{D}$ & $1.52 \times 10^{-5}$ & 59 & 45 \\
\hline
\end{tabular}


Table 3 shows the horizontal and vertical standard deviation and the maximal horizontal ATC calculated with equation 2 for each experiment (different distance from release point), for stability class $\mathrm{D}$ according to Pasquill classification.

\section{Results}

\subsection{Comparison of standard deviations (horizontal / vertical) between experimental measurements and calculated with Briggs urban model.}

Figure 5 shows a comparison between horizontal standard deviation $\sigma_{\mathrm{y}}(\mathrm{m})$ obtained with the experimental measurements and those calculated with Briggs urban model as function of distance from release point for the three stability class B, C and D according to Pasquill classification. Good coherence for the stability conditions B, C and D appears. For distances higher than $370 \mathrm{~m}$, the horizontal standard deviation could not been obtained because fitting a Gaussian curve was not possible. This is due to the fact that the distance between two horizontal sampling systems was fixed to $20 \mathrm{~m}$ during the experiments so when the release point is far from sampling systems the measured concentrations of $\mathrm{SF}_{6}$ have shown slight differences between each other.

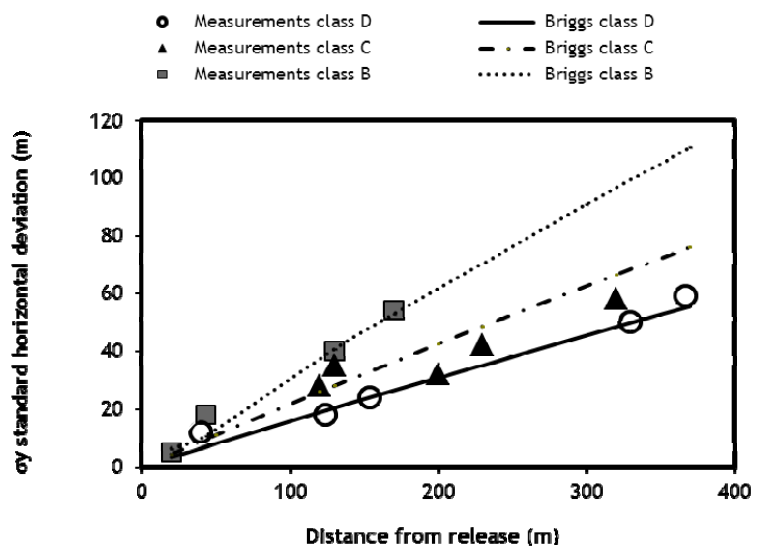

Figure 5: Horizontal standard deviation $\sigma_{\mathrm{y}}(\mathrm{m})$ deduced from experimental measurements compared to $\sigma_{\mathrm{y}}(\mathrm{m})$ calculated with Briggs urban model, for the different stability class according to Pasquill classification (B, C and D) as function of distance from release point.

Figure 6 shows a comparison between vertical standard deviation $\sigma_{\mathrm{z}}(\mathrm{m})$ obtained with the experimental measurements and those calculated with Briggs urban model as function of distance of release point for the three stability class $\mathrm{B}, \mathrm{C}$ and D according to Pasquill classification. Good coherence for the stability 
conditions B, C and D appears. However, the vertical standard deviation as the horizontal one could not been obtained for higher distances than $370 \mathrm{~m}$ because the vertical sampling system was not high enough when the release point was far. In fact, the obtained ATC values have shown slight differences between each other so fitting a Gaussian curve was not possible in these cases.

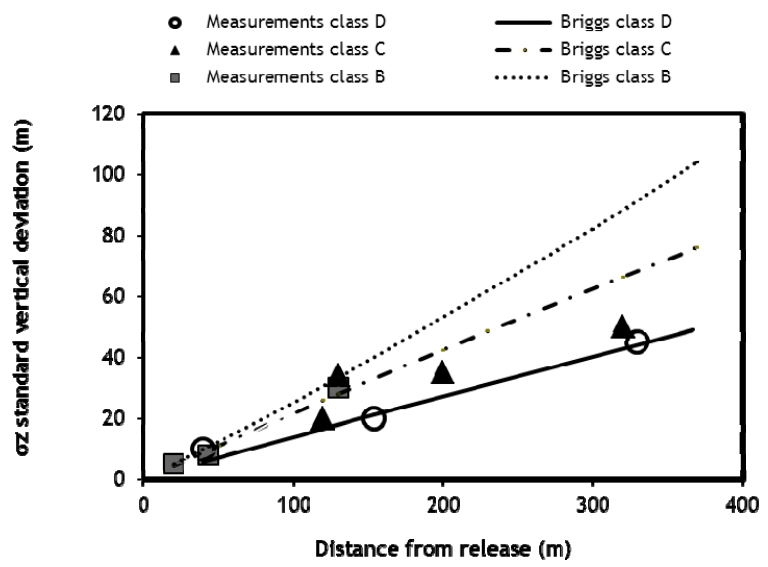

Figure 6: Vertical standard deviation $\sigma_{\mathrm{z}}(\mathrm{m})$ deduced from experimental measurements compared to $\sigma_{\mathrm{z}}(\mathrm{m})$ calculated with Briggs urban model, for the different stability class according to Pasquill classification (B, C and D) as function of distance from release point.

\subsection{Comparison of horizontal ATC between experimental measurements and calculated with Briggs urban model}

Figure 7 compares the ATC $\left(\mathrm{m} . \mathrm{s}^{-3}\right)$ maximal obtained with the Gaussian curves fitted to experimental measurements for the three stability class B, C and D and calculated with Briggs urban model with respect to the distance from the release point. Trend curves added for each stability class show that in case of class B and $\mathrm{C}$ for atmospheric conditions the ATC decreases faster than for class D when the distance from the release point increases. No obvious difference could be confirmed between ATC trend curves for class C and class D.

The comparison between the trend curves obtained from experimental measurements shown in Figure 6 for the three stability class B, C and D with the Briggs urban model is shown in Figure 7. At small distances the curves obtained with the Briggs urban model converge quicker than the one obtained with experimental measurements. No difference is detected between class B and C with experimental measurements contrary to Briggs model were ATC decreases faster for class B. More measurements are needed at high distances to confirm or invalidate the non-difference between ATC with respect to the distance to the release point between class $\mathrm{B}$ and class $\mathrm{C}$. 


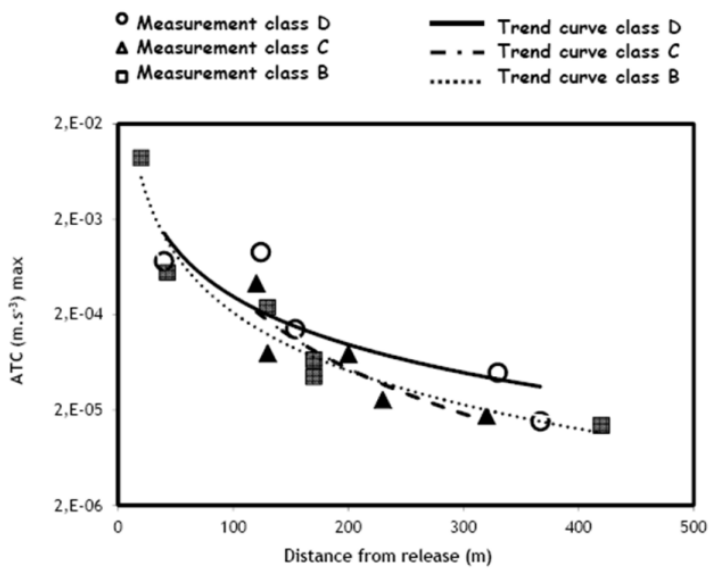

Figure 7: ATC $\left(\mathrm{m}_{\mathrm{s}} \mathrm{s}^{-3}\right)$ maximal with respect to the distance from release point $(\mathrm{m})$ for the three stability class $\mathrm{B}, \mathrm{C}$ and $\mathrm{D}$ according to Pasquill classification.

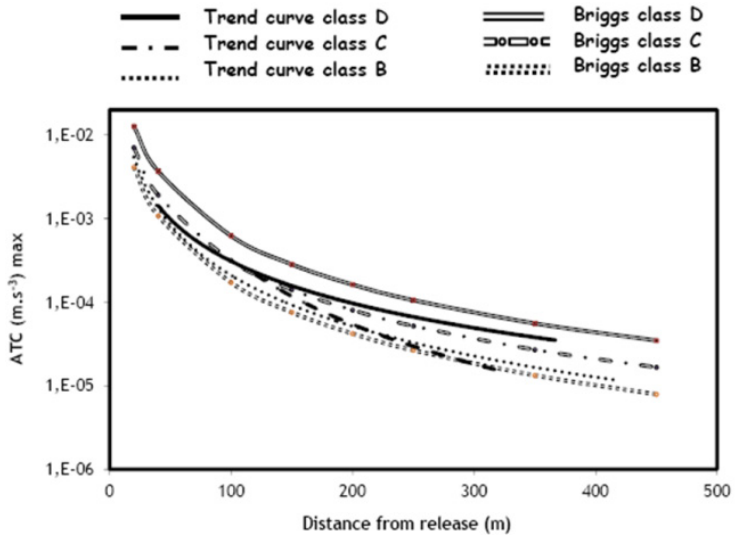

Figure 8: Comparison between trend curves of ATC $\left(\mathrm{m} . \mathrm{s}^{-3}\right)$ max obtained from experimental measurements with Briggs urban model with respect to the distance from released point for the three stability class B, C and D according to Pasquill classification.

\section{Conclusion}

The experimental work in the city of Nantes helped preparing a data base that could be used to reduce the uncertainty for any $3 \mathrm{D}$ dispersion model in urban

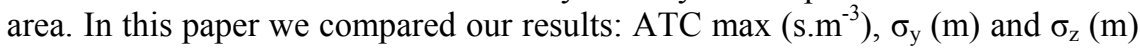
with the values predicted with Briggs urban model.

In terms of horizontal standard deviation $\sigma_{\mathrm{y}}(\mathrm{m})$, a good agreement was found between experimental results and Briggs urban model for the three stability class 
B, C and D according to Pasquill classification. However this agreement was only verified for distances between release point and sampling systems that did not accede $370 \mathrm{~m}$. In fact the distance between two horizontal sampling systems was fixed to $20 \mathrm{~m}$ so when the release point was far from sampling systems the panache is expected to get larger. To detect a Gaussian form of the curve the more we get farer from the source the more sampling systems should be away from each other. This point will be taking into account during the next experimental campaign that takes place in the same city (Nantes) in June 2012.

In terms of vertical standard deviation $\sigma_{z}(\mathrm{~m})$, a good agreement was found between experimental results and Briggs urban model for the three stability class $\mathrm{B}, \mathrm{C}$ and D according to Pasquill classification. However this agreement was only verified for distances between release point and sampling systems that did not accede $370 \mathrm{~m}$. In fact the vertical sampling systems were not high enough and were not separated enough to detect a significant differences between measurements. This point will be also taking into account during the next experimental campaign that takes place in the same city (Nantes) in June 2012.

In terms of ATC, the comparison between the trend curves obtained from experimental measurements of the maximal ATC with respect to the distance from release point for the three stability class $\mathrm{B}, \mathrm{C}$ and $\mathrm{D}$ with the Briggs urban model showed that Briggs urban model overestimate slightly the converge of the curves between the stability classes at small distances from the release point. No difference is detected between class $\mathrm{B}$ and $\mathrm{C}$ with experimental measurements contrary to Briggs model were ATC decreases faster for class B. More measurements are needed at high distances to confirm or invalidate the nondifference between ATC with respect to the distance to the release point between class B and class $\mathrm{C}$.

Finally in case of accidental reject we recommend the Briggs urban model to estimate the horizontal and vertical standard deviation of the plume for distances that do not accede $370 \mathrm{~m}$.

More experiment in the future will be held to evaluate the efficiency of Briggs urban model at higher distances. Also new experiments will be conducted to obtain better qualification of the plume widths principally as a function of roughness. Finally new experiments will be done in strong stability conditions.

\section{Acknowledgements}

We would like to thank ANR Vegdud, fluSAP and the staff of the Ecole central de Nantes for their contribution to the successful conduct of the experimental campaign.

\section{References}

[1] Mestayer P. et al., FluxSAP 2010 Experimental campaign overran heterogeneous urban zone, Part 1: heat and vapor flux assessment, HARMO 14, Kos Island, Greece, pp. 433-437, 2011. 
[2] Crabol B., Methodes d'evaluation de la dispersion des gaz dans l'atmosphère, cours 53 pp., 1996.

[3] Doury A.,experiment Une méthode de calcul pratique et générale pour la prévision numérique des pollutions véhiculées par 1 'atmosphère. Rapport CEA-R- 4280, 1976.

[4] Pasquill F., Estimation of the dispersion of windborne material. Meteorological Magazine, 90, pp. 33-49, 1961.

[5] CERC, ADMS 4.0 User Guide. Cambridge Environmental Research Consultants (CERC), 2009.

[6] Briggs G.A., Diffusion Estimation of Small Emissions. Atmospheric Turbulence and Diffusion Laboratory: Oak Ridge, TN Contribution No.79, 1973.

[7] McElroy J.L. and Pooler F., The St. Louis dispersion study: Analysis National Air Pollution Control Admin, US DHEW, Arlington, VA, p. 50 Pub. No AP-53, 2, 1968.

[8] Connan O., Leroy C., Derkx F., Maro D., Hébert D., Roupsard P., Rozet M., Atmospheric dispersion of an elevated release in a rural environment: Comparison between field $S_{6}$ tracer measurements and computations of Briggs and ADMS models, Atmospheric Environment, 45, pp. 7174-7183, 2011.

[9] Finn D., Clawson K., Carter R., Rich J., Eckman R., Perry S., Isakov V., Heist D., Tracer studies to characterize the effects of roadside noise barriers on near-road pollutant dispersion under varying atmospheric stability conditions. Atmospheric Environment, 44, pp. 204-214, 2010.

[10] Hanna S. and Baja E., A simple urban dispersion model tested with tracer data from Oklahoma City and Manhattan. Atmospheric Environment, 43, pp. 778-786, 2009.

[11] Britter R., DiSabatino S., Caton F., Cooke K.M., Simmonds P.G., Nickless G.. Results from three field tracer experiments on the neighbourhood scale in the city of Birmingham UK. Water Air and Soil Pollution, 2, pp. 79-90, 2002.

[12] Briggs, G.A., Analytical parametrizations of diffusion - the convective boundary layer. Journal of Climate and Applied Meteorology, 14, pp. 1167-1186, 1985.

[13] Maro, D., Calmet I., Mestayer P., Goriaux M., Hébert D., Connan O., Letellier B., Defenouillère P., Rosant J.M., Rodrigues V., FluxSAP 2010 experimental campaign, part 2: quantification of plume vertical dispersion during a gas tracer experiment using a mast and a small tethered balloon. HARMO, Kos Island, Greece, pp 438-442, 2011. 